\title{
"OS PARENTES QUEREM A MINHA PRESENÇA": SOBRE A CONTINUIDADE DAS COSMOLOGIAS KAINGANG E OS ENGANOS DE UM ESTADO COLONIAL
}

\author{
CLÉMENTINE MARÉCHAL ${ }^{1}$ \\ UFRGS
}

\begin{abstract}
RESUMO: $O$ "xamanismo" é abordado a partir de uma viagem com Iracema Ga Rã , uma mulher kaingang em deslocamento da vila Jari, em Viamão-RS, até a aldeia de Kandóia, no planalto rio-grandense. Ela vai dar seu apoio a parentes fragilizadas diante do encarceramento de cinco lideranças, após a morte de dois pistoleiros que mantinham uma criança kaingang refém, no mês de maio de 2014. Nesta viagem, foca-se na importância das relações entre humanos e extra-humanos enquanto via de potencialização e de fortalecimento do povo, principalmente em contextos adversos. Assim, busca-se maior compreensão do "xamanismo kaingang" enquanto motor de resistência e da luta pela terra e parte de uma cosmopolítica própria.
\end{abstract}

PALAVRAS-CHAVE: kaingang; xamanismo; cosmopolítica; luta pela terra.

RESUMEN: El "chamanismo" abordado es abordado a partir de un viaje com Iracema, uma mujer kaingang que viaja de la vila Jari em Viamão hasta la aldeia de Kandóia. Ella fue a dar su apoyo a parientes fragilizados después del encarcelamiento de cinco líderes después de la muerte de dos pistoleros que mantenían un niño kaingang como rehén. En este viaje, me enfoco en la importancia de las relaciones entre humanos y extra-humanos viéndolas como vía de potencialización y fortalecimento de un pueblo, principalmente en contextos adversos. Así, buscamos mayor comprensión del chamanismo kaingang como cosmopolítica, motor de resistencia y de lucha por la tierra.

PALABRAS LLAVES: kaingang; chamanismo; cosmopolitica; luta pela terra.

RESUME: Le chamanisme est abordé ici a partir d'un Voyage avec Iracema, une femme kaingang qui voyage du quartier Jari à Viamão jusqu'à Kandóia. Elle part pour donner son soutient à ses parents fragilisés lors de l'emprisonnement de cinques chefs kaingang après la mort de deux mercenaires qui retennaient en otage un enfant kaingang. Je m'enfoque dans ce voyage, sur les relations entre humains et extra-humains, relations que j'entends comme un moyen de potencialization et de fortification du peuple, surtout dans des contextes adverses. On cherche donc une meilleure compréhension du «chamanisme kaingang» en tant que cosmopolitique, moteur de resistance et lutte pour la terre.

MOTS CLES: kaingang; chamanisme; cosmopolitique; lutte pour la terre.

\footnotetext{
${ }^{1}$ Licenciada em etnologia pela Universidade Paris X, Nanterre, com trabalho com populações mineiras na Bolivia e trabalhadores migrantes no metro de Paris. Mestre em Antropologia Social pela Universidade Federal do Rio Grande do Sul, com foco na etnologia indígena. Possui interesse especial na procura de escritas colaborativas e conexões entre colonialidade e xamanismo. E-mail: clementine.marechal@yahoo.com.
} 
ABSTRACT: In this paper, we approach the "shamanism" topic through a trip with Iracena Ga Rã, a Kaingang woman traveling from Vila Jari, in the city of Viamão (Rio Grande do Sul State) to the Kandóia Village, northeastern Rio Grande do Sul State. She's going to give her support to relatives, for five indigenous leaders have been imprisoned after the death of two gunmen who were maintaining a Kaingang child hostage, in may 2014. On this trip, the relationship between humans and extrahumans is in evidence, as means to potentize and strengthen the group, specially in unfavorable contexts. Thus, a greater understanding of the " Kaingang shamanism » is pursued, the shamanism as an engine of resistance and struggle for land, as well as a part of a particular cosmopolitics system.

KEYWORDS: kaingang; shamanism; cosmopolitics; struggle for land.

\section{Introdução}

Procuramos a força através do fogo, a água é a clareza, a árvore é a vida e a terra é a mãe... (Iracema Ga Rã Nascimento, entrevista em 4 de junho 2014).

Nesse trabalho, nos propomos apresentar experiências compartilhadas entre uma mulher kaingang kujà ${ }^{2}$, Iracema Ga Rã Nascimento, e uma amiga sua, "estudante de antropologia". Sonhos que deram lugar a várias viagens no faroeste ${ }^{3}$ do Rio Grande do Sul serão o foco central do artigo. Sonhos que nascem de uma trajetória de vida permeada por esforços e profunda vontade de "apoiar" um povo em luta pela terra. Sonhos que precisam ser levados a sério quando realmente se quer "entender" como "os Kaingang"4 entendem, vivem, se relacionam

\footnotetext{
2 Segundo Rogério Rosa (2005, p. 133), o termo kaingang kujà se refere a uma pessoa que seria "responsável pelo equilíbrio das relações dos seres visíveis e invisíveis que habitam no mundo-aqui e no mundo-outro". Trata-se, para ser breve, do "pajé" dos Kaingang. Tentaremos, nesse artigo, através de um exemplo etnográfico específico, mostrar que o kujà, antes de tudo, é uma pessoa capaz de se relacionar intensamente com outros (sejam mortos, jãgré ou fóg), numa procura para manter ou restabelecer o equilíbrio harmônico preciso ao bem-viver kanhgág, incluindo nessa concepção do bem-viver, uma necessidade de luta pela retomada das terras kaingang.

${ }^{3}$ Uso o termo faroeste em referência aos diversos "encontros", "desencontros" e atritos entre colonos e Kaingang que tiveram lugar no período da nossa pesquisa (2013 e 2014). Encarceramento, perseguições (cosmo)políticas, ameaças de mortes, todo tipo de violência por parte dos fazendeiros, e apoiados (em quase todas as situações) pelas forças policiais. Para maiores informações sobre esses acontecimentos, recomendo a página do Grupo de Apoio aos Povos Indígenas no Facebook (https://www.facebook.com/pages/GAPIN-GRUPO-DE-APOIO-AOS-POVOS-INDIGENAS/188342354 524505) e o site do Conselho Indigenista Missionário (www.cimi.org.br ).

${ }^{4}$ Ressaltando, porém, aqui que não podemos encerrar todas as pessoas que se autorreconhecem como os
} 
e compõem seu território hoje... Porque esses sonhos ressaltam a importância de continuidades cosmológicas que hoje, em um contexto de perseguição política e violência, seja policial, estatal ou agrária no interior do Rio Grande do Sul, ressaltam a sua inscrição em uma cosmopolítica (STENGERS, 2005) que constrói dinamicamente a luta pela terra.

Nesse sentido, nossa perspectiva se inscreve numa procura para entender o "xamanismo" kaingang como uma prática viva na ação (INGOLD, 2012). Os estudos brindados por muitos outros antropólogos (CHAUMEIL, 2000; CRÉPEAU, 1997; BAPTISTA DA SILVA, 2002; ROSA, 2005) são ferramentas teóricas e conceituais de grande ajuda, que ressaltam o xamanismo kaingang como um sistema de pensamento complexo (LANGDON, 1996). Porém, vejo aqui pertinente me aproximar desse conceito a partir de uma etnografia, desde "a ação", no intuito de aportar talvez novos elementos, desde outra perspectiva.

Trata-se de uma tentativa de dar voz e vez a Iracema, uma mulher kaingang kujá que desde seus nove anos "trabalha" ${ }^{5}$ para os seus, se comunicando através dos sonhos, com "outros" e assim adquire poderes para influenciar sobre os acontecimentos atuais nas comunidades que dela necessitam. O objetivo central desse trabalho é, então, ressaltar essas experiências "xamânicas" como um dos motores da resistência kaingang frente à empresa colonial atual.

A proposta metodológica aqui segue duas vias. Primeiro, se inscreve numa perspectiva de uma etnografia do particular (ABULUGHOD, 1991). Nesse sentido, tentaremos dar visibilidade a relações e conexões, que nesse caso especifico, estão sendo agenciados por uma mulher. Longe de querer entrar em uma discussão sobre gênero nas "sociedades kaingang" trata-se de colocar o foco em Iracema Ga Rã, e, a partir de uma perspectiva "particular" e relacional, entender como a luta pela terra está sendo vivida além dos espaços "políticos" visíveis. Consequentemente, a proposta metodológica se faz através do

\footnotetext{
"Kaingang" em uma mesma categoria, pois as pessoas, mesmo pertencendo a um mesmo grupo étnico, têm trajetórias de vidas e viveram os encontros (e desencontros) a partir de uma experiência histórica distinta, pela qual as suas relações de hoje com o mundo atual é necessariamente entendida e vivida de maneira diferente.

${ }^{5}$ Uso esse termo porque é assim, em português, que Iracema se refere às experiências xamânicas que ela faz cotidianamente. Se referre a isso como a uma prática que precisa de continuidade e certo esforço; talvez por isso o termo traduzido em português mais parecido para ela é o de "trabalho".
} 
seguimento dos sonhos e das viagens de Iracema. Ressaltamos, então, uma necessidade de pesquisa, se envolver de forma itinerante em vez de interatuante:

Se, ao transformar a terra em superfície ou encarcerar corpos, nós bloqueamos essas trocas, nada poderá viver, enquanto reproduzir envolve um procedimento de interação, seguir envolve itineração (INGOLD, 2012, p. 25-44).

Paralelamente, trazemos aqui o desenho de Iracema, que expressa, nos seus termos, seu próprio entendimento e suas vivências do "xamanismo" ligado à luta pela terra. Nesse sentido, também é importante que esse artigo seja reconhecido como resultante de uma colaboração, em uma busca pela simetrização das relações entre os predeterminados "pesquisadores" e "pesquisados". Isto é, talvez, uma maneira de tentar romper - embora estejamos colocadas em uma sala de aula (por si só, ocidental e civilizada) - com as hierarquias predeterminadas. Não podemos esquecer também que essa experiência se inscreve em um processo de duplo afetamento, ${ }^{6}$ no qual tanto a vida da "estudante" como a vida da "kujä" foram se transformando, permitindo, assim, talvez, um conviver intenso do qual esse trabalho é o resultado.

Antes de começar os relatos das nossas itinerações (seja nos sonhos ou nas viagens), vejo pertinente contextualizar os momentos nos quais viajamos, muito ligados a uma luta histórica pela terra enfrentada por vários "grupos" Kaingang.

\section{Breve percepção sobre a situação dos encontros entre colonos, Kaingang e agentes do Estado do Rio Grande do Sul}

Penso em nossos acampamentos, temos que pensar em

\footnotetext{
${ }^{6}$ Quando Jeanne Favrett-Saada (1986) ressalta a importância de o etnógrafo ser "afetado" (no seu caso, acreditar nos seus interlocutores), quero indagar aqui que o fato de ser afetado, me parece, se faz em um duplo sentido: se o pesquisador se sente afetado pelos "novos mundos" que vai conhecendo no percurso etnográfico, o "pesquisado" também acaba sendo afetado pela vida, pelo mundo do "pesquisador". Isto é uma das grandes riquezas (trocas) que permite a prática da etnografia, desde o momento no qual o "pesquisador" está também disposto a abrir sua vida ao "pesquisado". Em todo caso, trata-se de relacionamentos nos quais, como dizia Roy Wagner (2010), o pesquisado deve estar disposto a passar por uma mudança de personalidade.
} 
uma solução. Será que nos achamos? Se botamos 5000 índios em cada acampamento, aí eles (os brancos) têm que arrumar 10000 soldados, isso é clima de guerra. Se não montar uma estratégia estamos fundidos, porque a justiça, ela não vem de onde vocês acham que vem. Essa terra que se conquistou não foi nem a Funai nem a justiça. 200 índios para cuidar todas as retomadas, assim fizemos ${ }^{7}$. Pela justiça, eu não acredito, a Funai, estão todos com os pés e as mãos atadas (Zé Lopez ${ }^{8}$, encontro do Conselho Estadual dos Povos Indígenas, Grito da Floresta, Nonoai, setembro de 2014.)

Nós (tanto antropólogos como indígenas) nos inscrevemos num contexto permeado por lutas pela terra, que tendem a ser consideradas pelos Kaingang como uma "guerra de papel" . Porém, no ano passado, a guerra de papel foi tensionada, dando lugar a várias situações de confronto direto, tanto com agricultores como com seus aliados policiais e agentes estatais. Muitas mobilizações indígenas foram organizadas, tanto na cidade de Porto Alegre, frente às autoridades públicas, como nas terras do interior do estado, em conflito direto com os colonos.

Existem, hoje, no Rio Grande do Sul, terras indígenas (T.I.) demarcadas pelo Estado. Desde 1988, com o nascimento da nova Constituição Federal, o Ministério da Justiça está encarregado de demarcar terras indígenas em todo o país, processo que, não podemos negar, propiciou algumas "vitórias", sobretudo na região amazônica (SANTILLI, 2001; ALBERT, 2004). Porém, no sul do país, esses processos seguem sendo complexos. A região está ocupada por agricultores e fazendeiros, produtores de soja, gado e milho, produtos destinados antes de tudo à exportação. Soma-se o fato de os políticos dos municípios onde os indígenas reivindicam as suas terras estarem vinculados, até mesmo por laços de parentesco, com os agricultores,

\footnotetext{
${ }^{7}$ Aqui, Zé Lopez se refere à retomada de uma parte da T.I. Nonoai nos anos 1990, que tinha sido invadida pelos colonos.

${ }^{8}$ Zé Lopez é cacique da T.I. Nonoai há várias décadas.

${ }^{9} \mathrm{O}$ "papel" é reconhecido como a nova arma de guerra dos brancos contra os indígenas. Pois a absurda burocracia da qual sofrem os povos indígenas para poder ter acesso seja às suas terras, seja a políticas públicas faz com que eles entendam esses mecanismos como uma nova forma de etnocídio. É comum ouvir de parte dos indígenas que agora os brancos estão matando eles como papéis... Para ganhar essa guerra de papel, vários interlocutores kaingang ressaltam a necessidade de se preparar, nos termos dos brancos, e, assim, ter uma aproximação e um conhecimento mais agudo da burocracia branca...
} 
que, muitas vezes, estão organizados em sindicatos rurais. Observa-se aqui uma "afinidade" econômica e política entre eles. Esta "afinidade" entra em conflito direto com as reivindicações dos povos indígenas que lutam pelos seus territórios e por suas perspectivas de relação com a terra e não de objetivação da mesma.

Imagem 1 - Desenho de Iracema: Os sonhos e a viagem.

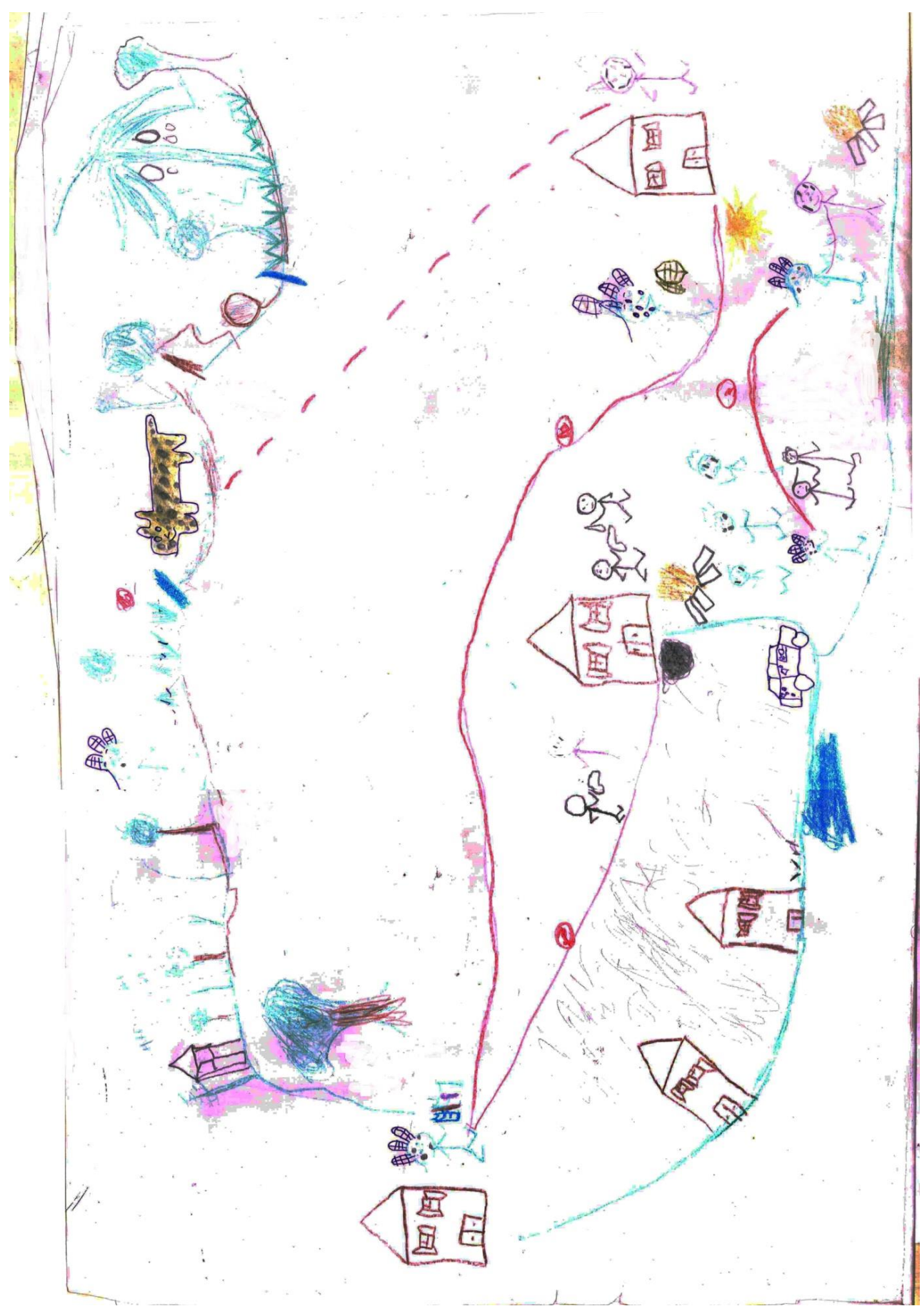


No dia 28 de abril de 2014, a comunidade de Kandóia, situada nos municípios de Faxinalzinho e Benjamin Constant (RS), realizou um bloqueio na estrada de acesso a Faxinalzinho, reivindicando, uma vez mais, o fim do processo de demarcação de suas terras. Para poder concluí-lo, faltava apenas que o ministro da Justiça assinasse o laudo já realizado, encaminhando a indenização e a realocação dos agricultores que ocupam atualmente o território indígena. Nesse mesmo dia, agricultores manifestaram seu desconforto com o fechamento da estrada: tentaram sequestrar uma das crianças indígenas no meio do bloqueio, e, consequentemente, o desconforto tornou-se um confronto entre os dois bandos, os enfrentamentos acabaram com a morte de dois "agricultores" 10 . No dia 9 de maio, lideranças kaingang da comunidade de Kandóia foram convocadas a uma reunião de "conciliação" em Faxinalzinho, à qual chegou primeiro a polícia militar para prender as lideranças e levá-las até a superintendência da Polícia Federal em Porto Alegre. Os cinco Kaingang estiveram presos até o dia 21 de junho no presídio de Jacuí, em Charqueadas (RS).

Itinerações, sonhos e relações: conectando mundos...

É no meio desse panorama de tensões que Iracema sonhou com uma kujà conhecida dela. Vendo a necessidade de se comunicar com seus parceiros, Iracema fez um jejum de dois dias. Uma das suas mestras, Marcolina ${ }^{11}$, se comunicou com ela no primeiro sonho que ela teve, pedindo ajuda para seu povo.

Primeiro foi o sonho com Marcolina, ela disse para mim que eu ia a sonhar com a mãe do cacique sem que eu soubesse que ia a precisar de apoio, a kujà me contou pelo que estava passando. Ela pediu pra mim levar esses remédios que pudesse usar para fortalecer ela e o seu filho e eu nem sabia quem que era o filho dela ${ }^{12}$.

\footnotetext{
10 Para maiores informações sobre os fatos e as suas consequências na terra de Kandóia, ver: Pronunciamento da comunidade Kandóia/Votouro, Espaço Ameríndio, v.8, n.1 (2014).

${ }^{11}$ Marcolina é uma das kujà na T.I. de Votouro, terra indígena próxima ao acampamento de Kandóia. Iracema a considera como uma das suas "mestras".

12 Aqui se refere ao cacique de Kandóia, Deoclides de Paola, preso no momento do relato.
} 
Duas noites sonhei e sonhei que levaria o remédio para mim fazer o meu trabalho (Iracema Ga Rã Nascimento, entrevista em 4 de junho de 2014).

Como podemos ver no desenho de Iracema, os primeiros sonhos, desenhados com linhas vermelhas (número 1 e 2 ), retraçam os encontros que ela teve com a sua mestra, Marcolina quem contou para ela em que situação se encontrava a comunidade. A casinha que se encontra no meio e do lado esquerdo do desenho é a casa de Iracema, em Viamão, no bairro Jari. Ela está saindo da sua casa. Aparece de cocar e podemos ver que tem umas bolinhas pretas pintadas na cara. Essas bolinhas a identificam com a sua metade cosmológica Kanheru. No primeiro sonho (trajetória vermelha número 1), estão uns policiais (homens de preto, armados de pistolas) apontando em direção a uma pessoa que está saindo de uma casa, em Kandóia. Podemos ver que essa pessoa está com a cara pintada com uns riscos pretos, longos e finos, identificando-a com a sua marca cosmológica Kamé. Trata-se de Madalena de Paula, quem, como podemos ver através da relação potencial de parentesco estabelecida pela complementaridade entre as duas marcas, é, como mencionado na fala de Iracema, sua jamrè.

As relações de afinidade entre os Kaingang se desenvolvem a partir da complementaridade entre pessoas que pertencem a metades (marcas, rá) cosmológicas diferentes. O(s) mundo(s) kaingang está(ão) conectado(s) em duas metades exogâmicas e complementares. Nos mitos $^{13}$ registrados por etnógrafos (NIMUENDAJU, 1993), os criadores do mundo são os dois gêmeos ancestrais kaingang, Kamé e Kanheru, quem, após o grande dilúvio, teriam criado os animais, as plantas e os "humanos". Assim, todos os elementos do(s) mundo(s) kaingang pertencem a uma das duas metades Kamé ou Kanheru (VEIGA, 1994; BAPTISTA DA SILVA, 2002). Os Kaingang chamam as metades de "marcas", já que cada metade está relacionada com uma forma, os seres Kamé são reconhecidos por uma marca larga e cumprida; ao contrário, os seres Kanheru, por uma marca redonda. As pessoas que pertencem à

\footnotetext{
${ }^{13}$ Iracema me relatou outra versão distinta do mito de origem que ela chama da "criação da humanidade". Não tenho o espaço aqui para expô-lo mas vejo interessante que se tomem em conta essas "novas" versões dos mitos kaingang, não com o intuito de encontrar neles uma nova "verdade", mas, sim, para entender tanto os processos de reelaboração de discursos e práticas ancestrais como dinâmicos, como para questionar essas verdades a partir de um "estudo" com um enfoque diferente...
} 
mesma metade são consideradas como irmãs. As relações de afinidade potenciais mais procuradas são as que se constroem entre pessoas que pertencem à metade oposta. $\mathrm{O}$ termo usado para descrever essa relação é o de jamrè, que, em português, poderia ser traduzido como cunhadio. Porém, essa tradução é muito imprecisa, pois os termos jamrè, má e $k a k r a^{14}$ levam consigo a necessidade da complementaridade brindada pela relação potencial entre pessoas que pertencem a metades-marcas opostas. Em via de regra, as pessoas que pertencem à mesma metade não podem se casar porque são irmãs. Como relata Iracema, um casamento com uma pessoa da mesma metade pode conduzir a problemas de saúde para os filhos:

É nossa marca o que importa mais, por exemplo, minha mãe se juntou com meu pai e eram primos, mas isso não importa, porque eles não são da mesma marca, minha mãe é kamé e meu pai era kanheru. Agora as pessoas que se juntam e que têm a mesma marca podem chegar a ter problemas, quase seguro que dá problema a partir do quinto filho, é que o sangue choca entre irmãos (Relato de Iracema, 05 de junho 2014.).

Sem entrar muito em detalhes, queria ressaltar a fala de Iracema para insistir na importância da busca pelo diferente na constituição da pessoa (BAPTISTA DA SILVA, 2002). A procura pelos afins passa necessariamente pela busca de um ou uma jamrè, e é essa relação que, uma vez potencializada, permitiria a pessoas, em um primeiro momento, consideradas como desconhecidas, se tornarem parentes.

No segundo sonho (trajetória vermelha número 2), Iracema está em Kandóia, com os remédios do mato, vẽnh-kagta, na mão, caminhando em direção à sua jamrè. Aqui, também, as duas parentes estão pintadas com suas marcas respectivas, o que reafirma a importância dessas marcas na relação de apoio que está se estabelecendo entre as duas mulheres.

Marcolina, que é a pessoa com quem Iracema menciona que sonhou, não aparece no desenho. Sendo sua kujà, ela está Ihe guiando,

\footnotetext{
${ }^{14} \mathrm{O}$ termo mà se refere a uma relação ego e uma pessoa maior da metade oposta do sexo feminino, talvez o termo mais próximo, em português, seria "tia". O termo kakrã, seguindo a mesma lógica, poderia ser traduzido como "tio", tomando em conta que essas relações não são do todo, mas que vão se criando na medida em que a relação se instaura.
} 
"abre" os horizontes para que Iracema saiba o que está acontecendo. Nesse sentido, a pessoa com quem se "sonha" não é necessariamente a pessoa que se "vê" no sonho, mas a pessoa que ajuda a ver, que potencializa, então, a "visão" da pessoa que sonha.

Depois desses dois sonhos, Iracema foi junto com João, o seu marido, Kẽgĩnh, um dos seus filhos mais novos, um estudante de antropologia e um ativista do movimento indigenista ${ }^{15}$, para buscar 0 remédio para levar a Kandóia, no morro Santana. O morro Santana é uma unidade de conservação que pertence à UFRGS ${ }^{16}$. Não pode ser habitado por nenhum ser "humano"17. Porém, é também o lugar onde Iracema colhe cipós e ervas necessárias, tanto para o cuidado dos corpos kaingang, como para estabelecer comunicação com outros seres (humanos e extra-humanos). É um dos poucos lugares onde ainda se pode encontrar certas ervas para esse tipo de "trabalho". Quando Iracema subiu no morro, o mĩg (onça) estava presente nos arredores, protegendo seus "afins" e afastando os vẽnh kuprĩg korég (pensamentos negativos ou "espíritos" ruins). Iracema afirma: "Eu me dou conta que ele está aí por seu cheiro, somente as pessoas com pensamentos bons, que estão dispostos, podem senti-lo".

No desenho, vemos a primeira trajetória verde (a linha verde que está mais encima). Iracema sai de cocar da sua casa e caminha em direção ao mato, no morro Santana. Podemos enxergar uma casinha preta, é a guarita dos guardas, situada na entrada do Morro Santana. Para entrar no morro, Iracema deve apresentar, cada vez, um cartão que deve ser, anteriormente, concedido pela burocracia, através de autoridades da UFRGS. Passando a guarita, Iracema caminha em direção ao mĩg, ainda com sua marca redonda pintada, se encontra com ele, que, como podemos ver, está marcado pelas mesmas marcas redondas que Iracema, ressaltando, assim, a relação de apoio que existe entre eles. Sendo marcado pela mesma marca que Iracema, o mĩg é quem

\footnotetext{
${ }^{15}$ Luis Fagundes.

16 Ver: http://www.ufrgs.br/sga/operacao-do-sga-da-ufrgs-1/projetos/unidade-de-conservacao-morrosantana .

17 "A ecologia política não busca proteger a natureza $e$ jamais procurou fazê-lo. Ela pretende, ao contrário, tomar a seu cargo, de maneira ainda mais completa, ainda mais misturada, uma diversidade ainda maior de entidades e de destinos. Se o modernismo pretendia dominar o mundo, ela, a ecologia, se embaralhou de uma vez" (LATOUR, 2004, p. 46).
} 
pode indicar e guiar Iracema para mostra-lhe qual é o vẽnh-kagta (remédio de ervas) que ela tem que levar para apoiar a sua jamrè.

E esse remédio que eu levei de aqui da cidade de aqui de Porto Alegre, do morro Santana, era para entregar na mão da minha jamrè, [...] Esse é um remédio que levemos daqui de Porto Alegre do morro Santana. Eu não peguei esse remédio como conhecedor, eu tive que tomar de novo meu chá de banho para me mostrar esse chá, quem que me mostra que é meu guia. (Iracema, entrevista realizada no dia 3 de outubro, na sua casa, bairro Jari, Viamão).

O mĩg indica para Iracema um remédio com folhas vermelhas (no desenho). Ele é seu jãgré (o seu guia) e como ela relata, ela precisa da sua ajuda para saber qual é e onde se encontra o vẽnh-kagta que ela precisa levar. Para estabelecer a comunicação com o mĩg, Iracema toma, anteriormente, outro banho de chá. Como podemos ver no desenho, o mĩg, jãgré de Iracema, se encontra entre duas fontes de goj (água), "lugar" onde Iracema deve tomar um banho de chá e, assim, consegue se comunicar com ele. Estabelecida a comunicação, ele aparece indicando para ela o vẽnh-kagta.

\section{Alegrando-nos com as parentes}

No desenho, o caminho da viagem está traçado por uma trajetória verde que sai da casa de Iracema. Como saímos de carro, Iracema não aparece sozinha na frente da casa. João, o marido de Iracema, seu filho mais novo, Kẽgĩnh, Rita e eu fomos as pessoas que acompanhamos Iracema. Dentro do carro, na linha verde, podemos ver que tem quatro bolinhas, essas bolinhas somos nós!

Podemos ver no desenho uma primeira casa. É a Ẽmã Kairu, em Carazinho, que se encontra na beira da estrada BR386. Fizemos na Ẽmã Kairu uma parada rápida. Como já conhecia as lideranças, fomos recebidos para tomar um chimarrão. Iracema conheceu Maria, a pessoa mais velha da aldeia, a avó de Ivo, o cacique da aldeia. Ao sair da aldeia, Iracema me comentou que Maria também era sua jamrè, já que pertencia à metade cosmológica Kamé. 
Imagem 2 - Itinerário da primeira viagem, de Porto Alegre até Kandóia.

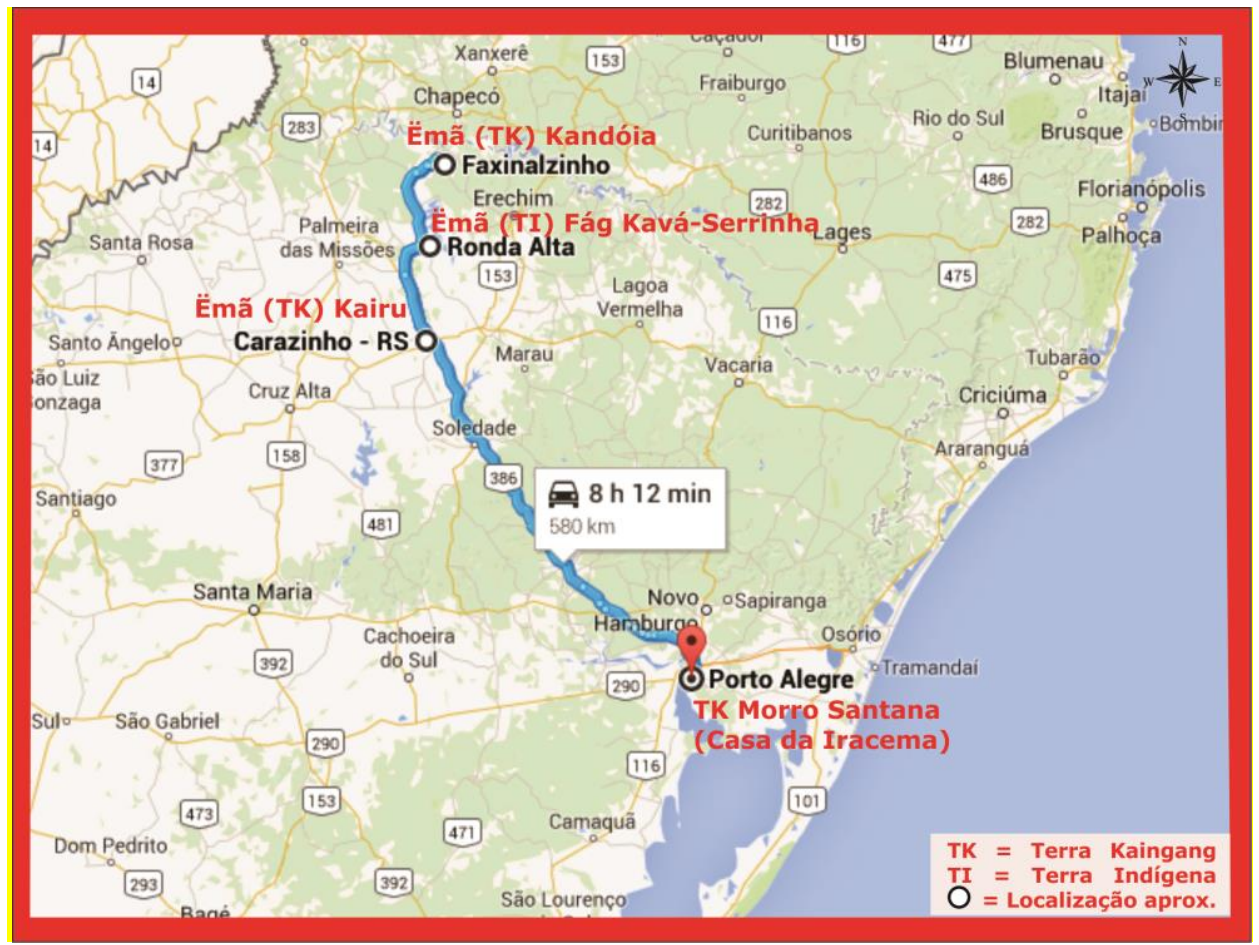

Fonte: elaboração própria.

Tínhamos saído de Porto Alegre sem nenhum contato com alguém de Kandóia, nem mesmo um número de telefone. Até então, no meu reduzido universo comunicativo, somente concebia que podíamos nos comunicar com a comunidade a partir de uma ligação telefônica, e andávamos todos (menos Iracema) preocupados pelo que poderia chegar a acontecer. De fato, uns colegas nossos, brincando entre eles, tinham-nos mencionado a possibilidade de que ficássemos de reféns dos Kaingang até a libertação das suas lideranças! Enquanto Iracema, alegre, conversava com Maria, Rita e eu procurávamos, através de Ivo e Vanessa, os telefones de pessoas que moravam nas Ẽmã Kandóia ou Votouro. Tentamos ligar para algumas delas, mas todos os celulares andavam desligados.

Depois de compartilhar um chimarrão, pegamos de novo a estrada em direção à casa da irmã de Iracema, Nilda. Nilda vive na T.I. Fág Kavá (conhecida, em português, como Serrinha), entre os municípios de Ronda Alta, Três Palmeiras, Engenho Velho e Constantina. 
Nossa viagem até a T.I. Fág Kavá foi acompanhada pelo ritmo monótono da paisagem: desertos de soja, inscritos no desenho com confusos riscos marrons. Campos e campos de soja se estendendo por quilômetros, sem parar. As palavras trocadas no carro se resumiam a nossa indignação cada vez maior.

Só soja, olha! Nem milho, nem feijão, só soja. Olha aí, nosso pinheiro, araucária como está diminuindo. Cadê os arvores nativos? Poderiam plantar coisas que dá para comer. Pitanga não tem, jabuticaba não tem (Iracema, conversa no carro, 19 de maio de 2014).

Comentava Iracema, olhando pelos vidros do carro. Sim, desertos verdes. De vez em quando, pingava uma araucária na paisagem, pequena marca que ressaltava que, no meio de um lugar arrasado pelo "progresso", ainda resistiam, firmes, algumas pegadas de vida.

Pelo meio-dia, chegamos à casa de Nilda e Zílio, onde ficamos para almoçar. A casinha de madeira do casal fica no fim de uma descida. Um lugar tranquilo, eles têm suas galinhas e plantações, entre elas, aipim. Ficamos um tempo fora, tomando sol e conversando. Enquanto a nora de Nilda cozinhava para nós uma comida deliciosa, seguíamos procurando o número de telefone de alguém de Kandóia. Iracema, por sua vez, andava pensativa e parecia confiante... Mas Nilda comentou com ela que sua tia, Cassilda, não morava mais em Kandóia, que se tinha mudado para a T.I. Votouro. Frente a nossas caras de preocupação e ansiedade, nos disse que iria "sair tudo bem...".

Logo depois, retomamos a viagem. Passando perto de Nonoai, paramos num posto de gasolina para pedir o caminho de Faxinalzinho. O jovem que nos atendeu, respondeu surpreso: "vocês estão indo para lá????". Seguindo os conselhos dos amigos e parentes Kaingang, decidimos evitar passar pelo centro de Faxinalzinho, que estava sendo vigiado pela polícia federal, e pegamos uma estrada de chão, desviando, assim, da possível vigilância e perseguição, fosse da polícia, fosse de colonos pistoleiros.

Fizemos uma parada logo após cruzarmos a barragem da hidrelétrica Monjolinho, que corta o fluxo do Rio Passo Fundo. O rio, goj, aparece no desenho de cor azul. Pegamos ali umas bergamotas, enquanto Iracema lembrava ter passado por lá quando criança, num 
tempo quando ainda não existia a barragem, cruzando a ponte em uma cesta nas costas do seu avô. Seguimos na estrada de chão por mais de quarenta minutos, passamos do lado da T.I. Votouro e um pouco mais a frente Iracema falou pra a gente parar o carro: "é aqui, olhem, tem um fogo no chão"18. Podemos ver no desenho, o carro parado, com quatro pessoas (bolinhas) dentro, e um pouco mais diante, do lado de Kandóia, um fogo no chão, gã kri pĩ. Iracema está saindo do carro, caminhando em direção a duas pessoas de preto (no desenho). Essas pessoas são sua tia e seu sobrinho, que, no fim das contas, seguiam morando em Kandóia. Estão presentes também várias mulheres kaingang, pintadas respectivamente com sua marca, jamrè e régre de Iracema, esperando-a perto do fogo.

Fomos recebidas, bem dizer, parece que já estavam esperando nós lá, todo mundo né, o grupo, o grande grupo lá na entrada da aldeia esperando nós chegar e nós não tínhamos avisado, mas no meu sonho já tinha avisado minha jamrè, né?: "eu vou chegar numa tarde não sei que horas", mas que eu ia chegar lá e só isso que confirmou a nossa chegada e receberam nós com alegria, brincando, dando risada e isso foi muito bom (Iracema, entrevista em 3 de outubro, na sua casa, bairro Jari, Viamão).

Por causa dos últimos acontecimentos na região, a ẽmã de Kandóia estava cercada com arame, pois era comum, desde então, as visitas dos policiais (uniformizados ou não), e colonos ao redor e dentro da aldeia. Quando descemos do carro, nos demos conta que um bando de mulheres de todas as idades estava em pé, na entrada da ẽmã, olhando para fora, com um sorriso na cara. Convidaram-nos a entrar na aldeia, nos sentamos do lado de muitas mulheres com quem Iracema conversou em kaingang. Rita e eu ficamos tão alegres quanto as mulheres kaingang. Mesmo sem falar a língua, nos sentimos acolhidas e sintonizadas com o ambiente do momento. Várias casinhas de madeira compõem a aldeia de Kandóia. O cheiro da fumaça permeava o ambiente e, por muita tristeza que podia reinar na comunidade, sentia-se uma incrível firmeza reinando no seio dela. As mulheres nos convidaram a

\footnotetext{
18 O fogo no chão expressa aqui uma marca de "reciprocidade" nos sonhos de Iracema. Em poucas palavras, o fogo está aceso porque as pessoas estavam esperando a sua (nossa) chegada.
} 
descer no fundo da aldeia, onde se encontrava um galpão grande. Entramos no galpão, tinha algumas pessoas esperando a gente. Sentamo-nos todos num banco, Iracema, seu filho Kẽgĩnh, eu, Rita e João, todos em linha, frente às pessoas da aldeia, que pouco a pouco chegaram. Em uns poucos minutos, o galpão se encheu de gente, mulheres, homens, crianças, cachorros, galinhas e também os mais antigos, os troncos velhos ${ }^{19}$. Pouco a pouco chegava mais pessoas, algumas pessoas fumando cigarros, outras tomando chimarrão. E ao momento de Iracema falar, todos ficaram atentos as suas palavras. Escutando o conforto vibrar na sua fala, Rita e eu ficávamos nos olhando, olhando para as pessoas, emocionadas, sem conseguir "acreditar" no que estávamos vivenciando. Era, pois, sentir na pele, o que Iracema tinha nos comentado durante a viagem toda, entrar dessa maneira, em sintonia com ela e, assim, com a comunidade.

Cheguemos lá, me receberam, né?... . Povo Kaingang, eu disse para eles em kaingang: olha, eu trouxe um conforto para vocês, eu sonhei assim, e é com a mãe da liderança de vocês que eu vim a conversar pessoalmente, confortar, né?, dar um apoio. E para ela acreditar que o filho dela vai estar bem, daqui a uns dias voltando. Mas eu não fui sozinha, eu convidei as minhas amigas, a Clementina e a Rita, como eu não tinha condições de ir e disse pra vocês, me fazem um favor, me levam pra lá, ir a confortar essa comunidade comigo, que eu preciso de vocês, e fomos para Kandóia (Iracema, entrevista em 3 de outubro, na sua casa, bairro Jari, Viamão).

Ela nos apresentou, e os Kaingang de Kandóia viram, na nossa presença, uma oportunidade para difundir e informar sobre a situação de isolamento pela qual estavam passando. Nos trouxeram suas impressões e sensações, que redigimos depois em um documento que logo circulou pelas redes sociais em vários lugares ${ }^{20}$.

Jantamos e passamos a noite na casa de Malvina, irmã de Cleci Pinto, esposa de Deoclides de Paula. Ficamos conversando até tarde com as irmãs e esposas das lideranças presas, fumando cigarros e

\footnotetext{
19 “Troncos velhos" é usado pelos Kanhgág para se referir às pessoas mais antigas do povo, os que têm um grande conhecimento.

${ }^{20}$ Pronunciamento da comunidade Kandóia/Votouro, Espaço Ameríndio, v.8, n.1 (2014).
} 
passando a limpo o documento. Conversamos com Cleci, que se preocupava muito pela alimentação do seu marido. Preocupada, passava muito tempo no telefone tentando ter acesso a informações sobre a situação do marido.

Cleusa, a irmã de Deoclides, me pareceu ser uma pessoa mais dura, forte. Não deixava mostrar sinais de tristeza, nem lágrimas, nem lamento; porém, uma pessoa muito atenciosa. Cuidava cada palavra colocada no texto que estávamos redigindo. Me deu de presente uma caixa de cigarros ao ver que o meu pacote de Beija-Flor tinha chegado ao fim.

Emocionada pela situação na qual estávamos todas, ficamos conversando de amores, saudades e brigas com a polícia durante horas. Horas, cujos cigarros ajudavam em aliviar a tensão, e as palavras nos traziam alegria no meio da desgraça. As duas mulheres não se lamentavam; indignadas pelo trato que receberam, se preocupavam com seguir adiante numa situação de isolamento.

Depois do encarceramento das lideranças, a escola fechou, e quando abriu de novo as crianças receberam insultos e maus-tratos por parte dos filhos dos colonos. Enquanto isso, 26 homens tinham recebido ordens judiciais, então, se arriscavam o mínimo possível a sair da aldeia. As mulheres eram as únicas que podiam sair da aldeia para buscar cipó, e, mesmo assim, se arriscavam a perseguições por parte dos colonos. Vi Cleci e Cleusa de novo quando vieram para Porto Alegre em junho para visitar Deoclides. Ficamos as quatro na casa de Rita e, nesse momento, conheci mais a Cleusa. Uma mulher solteira, que gosta de uma vida sem marido, gosta de poder viajar sozinha. Me relatou que tinha trabalhado como cozinheira. Me transmitiu uma sensação de dureza e firmeza que entendi, acho, somente quando conheci seu irmão Deoclides. Poucas palavras e uma expressão que, porém, eram capazes de transmitir tanta energia.

Aquela noite foi também movimentada para Iracema. Ela sonhou de novo com Marcolina. No desenho, o último sonho de Iracema aparece com a trajetória vermelha (número 3). Ela está em Kandóia, entregando, no momento do sol nascer, o remédio vẽnh-kagta para sua jamrè, Madalena de Paula. Como relata Iracema: 
E como levei lá o remédio, a kujà Marcolina apareceu lá na noite anterior [no seu sonho]. Marcolina falou pra mim deixar o remédio, ela é nossa mestre. Não precisei ver ela, já tinha sonhado com ela (Iracema, 05 de junho 2014).

Esse último sonho foi necessário para Iracema ter a "confirmação", a segurança que tinha que deixar o remédio com Madalena. Este sonho reafirma, nesse sentido, a conexão contínua que ela manteve com a kujà Marcolina, que, mesmo não estando presente "materialmente" com a gente e no desenho, esteve acompanhando-a durante toda a nossa viagem.

No dia seguinte, por fim, conheci Madalena, Iracema me apresentou para ela. De longe, ela me disse "ela é minha jamrè, ela é. Agora vou entregar os remédios para ela". Vi ela chegar, com os pés descalços, caminhando no barro molhado. Cumprimentei-a, tentando dar força com abraços e poucas palavras. Algumas lágrimas corriam pelo seu rosto, Iracema começou a falar com ela para confortá-la e, como vemos no desenho, a partir da trajetória verde, Iracema entregou o remédio para ela, ao redor de um fogo do chão aceso.

E esse remédio que eu levei de aqui da cidade de aqui de Porto Alegre, do morro Santana, era para entregar na mão da minha jamrè, que é a mãe da liderança cacique que foi perseguido e que estava preso, para ela queimar, de manhã antes do sol nascer, acompanhando o sol nascer e na parte da tarde quando o sol foge (Iracema, 05 de junho 2014).

É interessante ressaltar a presença do sol e da lua no desenho como na fala de Iracema. No desenho, a lua aparece em Kandóia, no momento no qual chegamos, já que chegamos de tarde-noite na aldeia, e assim, também, no momento do último sonho de Iracema. Em contraste, o sol aparece no momento da entrega do remédio. A aparição do sol, rã, e da lua, kysã, ressalta, mais uma vez, a expressão da complementaridade entre as duas metades, Kamé e Kanheru, necessária ao equilíbrio no mundo kaingang. O sol (Kamé) e a lua (Kanheru) se complementam, harmonizando, assim, o encontro e a troca entre Iracema (Kanheru) e Madalena (Kamé), fortalecendo muito mais que uma única pessoa. 


\section{Como os sonhos se tornam vivos}

Retomando o desenho, podemos ver que os sonhos de Iracema se conectam com os acontecimentos. A trajetória verde da nossa viagem acaba se juntando com a trajetória vermelha do sonho número 1 de Iracema. Essa mesma trajetória verde também segue paralela à trajetória vermelha do último sonho de Iracema. Essas conexões marcam no desenho a reciprocidade necessária para os sonhos poderem se tornar vivos. Sendo relacionais, os sonhos existem somente quando eles são recebidos por outra pessoa, que, pelo fato de "reconhecê-los", confirmam sua existência. Iracema ressalta que as mulheres de Kandóia já estavam sabendo da nossa chegada, sem que fosse "avisado" pelos meios de comunicação convencionais.

Elas estavam prontas pra chegar pessoas. As mulheres todas tinham tomado banho. A kujà Marcolina é avó ${ }^{21}$ dela [de Madalena]. No sonho, ela também sonhou com a sua kujà. A mãe do cacique tinha ido lá no Votouro dois dias antes e a kujà [Marcolina] já tinha falado que ia a chegar essa pessoa [Iracema], sua jamrè. Tinha falado que ia a vir gente de longe, não de Nonoai, não de Carazinho, mas de mais de 400 quilômetros. "É a tua jamrè", falou. "E ela vai trazer remédio para queimar e cuidar do teu filho". Ela já ficou esperando pessoas chegarem (Iracema, entrevista em 4 de junho de 2014, na sua casa, bairro Jari, Viamão).

Iracema ressalta aqui que sua jamrè, Madalena, também sonhou com a mesma kujà, Marcolina. Após ter sonhado com ela, Madalena foi visita-la na T.I. Votouro, onde ela mora, e, assim, ficou sabendo já da chegada de Iracema. Uma coisa que me parece interessante ver aqui é a figura da kujà Marcolina. Como falado antes, ela não aparece "materialmente", nem no desenho, nem na viagem. Porém, é ela quem possibilita que as várias relações sejam estabelecidas. Ela é a primeira em informar para Iracema qual é a situação em Kandóia, abrindo a "visão" dela no sonho, possibilitando desde já o início de uma relação

\footnotetext{
${ }^{21}$ Entende-se, pelo termo "avô", uma relação de parentesco geracional. Ser avô significa que Marcolina é da mesma metade cosmológica que Madalena, mas de duas gerações anteriores.
} 
entre Iracema e Madalena. Ela fortalece essa relação, aparecendo de novo no último sonho de Iracema, reafirmando para ela a necessidade de entregar os remédios que ela levou desde Porto Alegre.

A kujà Marcolina, nesse sentido, é a pessoa que impulsiona as relações desde o âmbito dos sonhos, inh ga kri vẽnh péti (mundo dos sonhos na terra), para o mundo "visível", inh ga kri. Iracema, guiada por Marcolina, coloca nesse mundo e na prática os conselhos de Marcolina. Madalena, por seu lado, também recebe informações por parte da kujà Marcolina. Nesse sentido, a importância da kujà Marcolina aparece aqui na sua grande capacidade em realizar conexões entre outra kujà, Iracema, sua "aprendiz", e Madalena, a pessoa que foi afetada pelo encarceramento das lideranças. É interessante ressaltar que, antes de sair de Kandóia, Madalena procurou Iracema de novo, elas foram tomar café da manhã juntas, em sua casa de madeira, no fundo da aldeia. Quando Iracema voltou, ela me mostrou uma cesta que Madalena tinha dado de presente para ela: "Olha, Clé, o presente que minha jamrè me deu, é um cesto igual aos que meus avós faziam...".

É assim também que as fronteiras entre o mundo "visível", inh ga kri, e os mundos invisíveis, o inh ga kri vẽnh péti e o nũgme (mundo dos mortos), o tempo passado e o tempo presente, tanto quanto as fronteiras entre o material e o imaterial se diluem nos acontecimentos. Aquela diluição deixa, assim, uma possibilidade para a comunicação entre dois kujà através dos sonhos, vẽnh péti, ter impactos para a continuidade da luta pela terra; que mais comumente é vista e relacionada, sobretudo, com agentes estatais de todo tipo, ou seja, com homens e reuniões públicas. Em respeito a isso, Iracema ressalta a necessidade das pessoas "acreditarem" no seu trabalho para facilitar sua continuidade. Ela me diz que, agora, poucas pessoas acreditam: "Nem meu marido, mas isso debilita a gente, debilita os nossos conhecimentos". Os sonhos, nesse sentido, devem ser entendidos como uma relação na qual as pessoas que rodeiam a kujà são pessoas fundamentais para os sonhos se tornarem "vivos".

Segundo Iracema, os pensamentos ruins, vẽnh kuprĩg korég, que podem se referir ao fato de ter uma visão muito fechada, quadrada e então reduzida do mundo, debilitam e enfraquecem o trabalho da kujà. Na passagem do mundo dos sonhos (mundo "invisível"), inh ga kri vẽnh 
péti, ao mundo "visível", inh ga kri, os sonhos se veem "confirmados" pelas pessoas "afetadas". Essa relação complementar entre o kujà e as pessoas debilitadas nos permite entender o xamanismo como uma relação na qual tanto o kujà quanto as pessoas que são alvos, nesse caso, do seu apoio são fundamentais para sua existência. É por isso que Iracema afirma que as pessoas que não acreditam nela debilitam o seu trabalho. Seus sonhos se potencializaram, como também outros dos seus conhecimentos, porque foram "levados a sério", por parte do povo Kaingang e também além dele.

Nesse sentido, as conexões entre mundos acontecem também além de um universo kaingang. No decorrer da viagem, somos nós, duas estudantes de Antropologia, que também ficamos afetadas pelos sonhos de Iracema. Entrar em sintonia com ela faz parte da reciprocidade e das "confirmações" que ela relata nas suas falas. Lembro-me de uma piada que fiz, no carro, chegando a Kandóia, quando não tínhamos conseguido nos comunicar com ninguém de Kandóia por telefone e que Iracema, despreocupada, falava que ela já tinha se comunicado com elas nos seus sonhos: "Bem ainda que tu sonhou, porque os sonhos, os policiais, eles, não podem grampear ${ }^{22}$. Assim estamos seguras...".

Dessa maneira, os impactos dos sonhos de Iracema transcendem o mundo "kaingang" e permitem que esses se tornem vivos além de uma relação entre duas kujà e uma pessoa afetada. É nesse sentido que podemos nos aproximar do conceito de cosmopolítica (STENGERS, 2005), ressaltando a luta pela terra como vivida e agenciada por múltiplas perspectivas, que, ao se complementar, reafirmam sua fortaleza e sua continuidade.

Stengers (2005, p. 15) ressalta que a ideia de cosmos na proposta cosmopolítica não possui representante, que ninguém fala em seu nome e que, assim, não precisa de consulta prévia para ser "aprovado"23. Nesse sentido, cosmopolítica abarca uma pluralidade de formas de "fazer política". Nas próximas páginas, nos referiremos à cosmopolítica

\footnotetext{
${ }^{22}$ De fato, todos os celulares das pessoas da aldeia de Kandóia tinham sido grampeados pela polícia.

${ }^{23}$ No texto original, "As for the cosmos, as it features in the cosmopolitical proposal, it has no representative, no one talks in its name, and it can therefore be at stake in no particular consultative procedure" (STENGERS, 2005, p. 15).
} 
kaingang como relacionada com a luta pela terra. Nesse sentido, é necessário ressaltar a importância dos sonhos e da viagem de Iracema para o fortalecimento dessa luta pela terra. Os processos coloniais seguem homogeneizando a política, reduzindo-a a espaços e modelos impostos e controlados pelo Estado. Nesses espaços, os saberes dos kujà não são reconhecidos porque escapam aos modelos ocidentais e assim não puderam ser (ainda?) controlados e reapropriados pelo Estado. Frente às populações indígenas, os Estados se comportam de maneira colonial, negando (ou não querendo se interessar) pelas formas diferentes de se relacionar com o mundo. Por exemplo: que organismo estatal ou indigenista daria financiamento para a viagem de uma mulher kujà que sonhou que tinha que entregar remédio para outra mulher, e que afirma que essa viagem é necessária para fortalecimento da sua comunidade? Que organismo estatal ou indigenista apoiaria as demandas de uma família kaingang que afirma que precisa viajar cada mês à terra dos seus parentes, já que as viagens fazem parte de uma cosmovisão própria que entende a relação com os parentes como parte do território? Que organismo estatal financiaria o transporte de uma família que precisa viajar para colher sementes e cipó necessários para a realização do seu artesanato?

Como ressaltava Iracema no $V$ Encontro dos Kujà, em novembro passado, na Ẽmã Tupé Pãn - Morro do Osso, antigamente, as comunidades kaingang eram "lideradas" pelos kujà, que, com o poder de comunicação e conexão que tinham com outros mundos, tinham capacidade de ajudar a comunidade, seja no âmbito "interno", seja em relação a outros povos, e também (talvez, sobretudo) na relação com os colonos.

A criminalização e perseguição dos kujà ao longo do tempo ressalta justamente o seu potencial "perigoso" para quem adota uma atitude etnocida. Os kujà foram e seguem sendo perigosos para quem considera a diferença um perigo. Para os Kaingang, o xamanismo, seja através dos kujà kajrẽn (conhecimentos dos kujä), seja desenvolvendo uma práxis xamânica em reuniões públicas, é uma potência que desafia cotidianamente as intenções coloniais e sua posta em prática.

Os processos coloniais transformaram os modelos "políticos" nas comunidades. Em várias comunidades hoje, quando chegamos, as 
lideranças se apresentam sendo "capitão 24", "coronel", "cacique", "soldados". Essas denominações, aparentemente, deixam ver uma "organização" militar (de fato herdada de uma imposição dos primeiros processos coloniais). Porém, na prática, os saberes dos kujà (e não somente dos kujä) não desapareceram e seguem conformando os universos "políticos". Não ficaram intactos, obviamente, os conhecimentos vão se produzindo, reelaborando-se na relação. Por isso, os sonhos e as viagens de Iracema devem ser entendidos como produto tanto da relação que ela leva com seus antepassados quanto das relações atuais que ela desenvolve com seus parentes e com o universo fóg. Uma relação, em todo caso, profunda e intensa com a luta pela terra que ela vem continuando a partir dessas conexões entre as diversas relações que desenvolve.

A proposta cosmopolítica toma esse tipo de utopia ainda mais longe, pesada pela lembrança que moramos em um mundo perigoso, onde, nada pertence à razão, onde qualquer proposta pode ser falsificada, onde, quem "inventou as políticas" também produziu os sentidos para reduzi-lo a um grande jogo vazio, deixando fora o que estava trabalhando, produzindo, ou destruindo, os nossos mundos ${ }^{25}$ (STENGERS, 2005, p.995-996).

O conceito de cosmopolítica está, nesse sentido, permeado não somente por "maneiras de fazer política", mas também pela expressão de um relacionamento diferente com o mundo. Expressões diferentes dos conceitos (território) e práticas (territorialidade) hegemônicas. O que nos permite aqui o conceito de cosmopolítica é ressaltar o que é comumente invisibilizado e desconsiderado.

No início de junho de 2014, Iracema, Rita e eu voltamos para

\footnotetext{
${ }^{24}$ O capitão, me falava Ivo na Ẽmã Kairu, em Carazinho, é quem se encarrega de resolver os problemas internos na comunidade. Problemas como o ciúmes, por exemplo. Porém, Iracema me relatou que, antigamente, que essa responsabilidade era sempre acompanhada pelas mulheres conselheiras, cuja importância foi desaparecendo com o tempo, notadamente com a chegada tanto das igrejas com do Estado, impondo modelos e padrões de organização social divididos por gênero.

${ }^{25}$ Tradução minha. No texto original: "The cosmopolitical proposal takes this type of utopia even further, weighted by the memory that we live with in a dangerous world, where nothing stands to reason, where any proposition may be falsified, where we who "invented politics" also produced the means to reduce it to a largely empty game, leaving outside what was at work, producing, or destroying, our worlds" (STENGERS, 2005, p.995-996).
} 
Kandóia. Dessa vez, acompanhadas do filho maior de Iracema, Katumé e de Kẽsé, o seu quarto filho. Após nossa primeira viagem, vendo a situação de isolamento na qual se encontrava a comunidade, tínhamos combinado com eles de fazer uma coleta de roupa e alimentos na UFRGS para levar a Kandóia. No dia anterior ao de nossa viagem, Cleci, a esposa de Deoclides de Paula, então preso no cárcere de Jacuí, ligou para nós, avisando que estavam, ela, sua cunhada, Cleusa e mais umas amigas, parando na Ẽmã Por Fi (São Leopoldo). No caminho, passamos pela aldeia. Como a irmã de Iracema, Terezinha, mora também em Por $\mathrm{Fi}$, tomamos o café da manhã com ela e logo nos encontramos com Cleci e Cleusa. Escolheram dentro do carro umas roupas para levar para seus familiares presos e para elas. Pois elas tinham chegado na região de Porto Alegre há vários dias e ainda não tinham conseguido ver os presos. A chuva, o frio e a tristeza, porém, não apagavam um eventual sorriso em seus rostos marcados pela saudade e ausência dos seus familiares. Reunidas na casa dos parentes das mulheres, compartilhamos um chimarrão, mesclando, na conversa, a atuação dos advogados e o mundial que estava por chegar. Rapidamente, tomamos a estrada em direção à Kandóia.

Chegamos de noite na comunidade. Juliana de Paula, enfermeira da comunidade, nos recebeu e nos levou até a casa de Malvina, cunhada de Deoclides de Paula, que, após ter nos levado para a mesma casa onde tínhamos ficado a vez anterior, nos preparou um delicioso jantar. No dia seguinte fomos levadas por várias mulheres da comunidade para conhecer a terra reivindicada. $\mathrm{O}$ intuito partilhado era juntar e difundir informações a respeito da situação na qual se encontrava a comunidade de Kandóia em relação à demarcação da terra. Malvina, junto a sua filha, e Madalena de Paula nos convidaram para caminhar pela estrada de chão que corta a terra que reivindicam. Iracema, caminhando de braços dados com sua jamrè, escutava atenciosamente as palavras de Madalena, reconhecendo, "nesse pedacinho de terra" as marcas kaingang.

Do outro lado da estrada de chão, na frente da casa de um dos colonos, Madalena apontava uma figueira antiga cujos frutos, antigamente, eram colhidos. A atual casa do colono era, pois, o lugar tradicionalmente ocupado por Madalena e seus avós há anos atrás. Ela 
nos comenta, secando suas lágrimas de indignação com a manga do seu casaco, que dando continuidade aos passos dos seus avós, aqui estão vivendo seus bisnetos.

Hoje, a estrada é uma fronteira, um limite que divide a aldeia e o território usurpado pelos fóg. Casas e terrenos protegidos com arame estão de frente com a aldeia de Kandóia. A casa do vice-prefeito de Faxinalzinho é uma delas. Porém, o território é marcado pela presença kaingang, antiga e atual. As araucárias acompanham o caminho e as lembranças das mulheres de Kandóia fazem viver o território, revelando-se, para nós, como um conjunto de relações tensas entre, por um lado, prefeitos, outros políticos e colonos e, por outro, os Kaingang.

Malvina e sua filha me levaram até o antigo cemitério da comunidade, do lado "interditado" da estrada. "O prefeito proibiu-nos de enterrar nossos mortos aqui, e queriam que tirássemos os que já estão mortos daqui", comenta Malvina. Desenterrar os mortos. Aquela era uma das "propostas" territoriais dos agentes estatais da região. $O$ cemitério está quase vazio, três pessoas enterradas. Uma delas é uma criança, que por falta de cuidados de parte da Funai ${ }^{26}$ não foi atendida a tempo para ser curada. Como os Kaingang em Kandóia não têm mais onde enterrar seus mortos, eles têm que caminhar até a T.I. Votouro para sepultá-los.

Voltando à aldeia, olhando para um araçá, Malvina se lembra do seu fruto vermelho e do goj fej (banho de flor) que seu avô lhe fazia. Até uma das suas netas leva, hoje, esse nome. Olhando para as casas dos colonos, Malvina se lembra dos taquarais gigantes. Relembra os tempos nos quais andava com seu avô buscando taquara no mato. Tinha cinco anos, seu avô colocava o cesto na cabeça e caminhavam até Erval Grande para vender os cestos: "Aquele tempo era bom, era só tirar, era tudo mato isso aí, agora tudo está destruído porque estão os brancos!", me explica. Apontando de novo no terreno ocupado pelos colonos, se lembra também do pé de guabiroba, e, apontando sua ausência com o dedo, comenta que seu avô colhia os frutos e o dava para ela comer nas viagens até Erval Grande: "Me lembro bem, sim!", afirma ela.

Iracema, acompanhando Madalena e tomando carinhosamente sua

\footnotetext{
${ }^{26}$ Como a criança, agora em 2015, teria 14 anos, quando morreu, o órgão estatal responsável da saúde indígena era a Fundação Nacional de Saúde (Funasa), que fazia parte do Ministério da Saúde.
} 
mão na intenção de confortá-la, comentava para nós, indignada, a situação crítica na qual a comunidade se encontrava. Se apresentava, pois, outra vez como mediadora. Na primeira viagem que fizemos a Kandóia, Iracema mediava mundos "visíveis", inh ga kri, com os "invisíveis", inh ga kri vẽnh péti, através dos seus sonhos, vẽnh péti. Com o mesmo intuito de apoiar sua jamrè, na segunda viagem, ela oferece sua ajuda manifestando a sua indignação para nós (e para a câmera presente no momento), transpassando, então, os mundos kaingang.

Os "trabalhos" da xamã, nesse sentido, implicam também ser afetado pela pessoa visada na relação: "Vim de longe sofrer aqui com meus parentes". Comenta Iracema na entrevista que fizemos com ela nesse mesmo dia, em Kandóia. São afeições que passam por mudanças da pessoa, no corpo. O rosto de Iracema se transformou, afetada, pela dor da sua jamrè. Os corpos kaingang se constroem pela absorção de substâncias complementares (ELTZ, 2011; CARVALHO ROSA, 2011). Dando força a Madalena, Iracema também assimila as substâncias da sua jamrè. E é justamente sua capacidade em equilibrar essas substâncias que permite a Iracema poder transpassar mundos mediando relações diversas.

Nesse sentido, o apoio dado a sua jamrè passa por sua capacidade em colocar-se na sua pele, tomando o seu ponto de vista. Esse, como diz Iracema, "sentir na pele", Ihe dá a possibilidade de comunicar para outros mundos, nesse caso, o mundo dos fóg, a dor da sua jamrè. Essa mediação é, pois, um motor para a luta pela terra. Diante da câmera, Iracema ressalta para nós:

Eu sou uma que luta desde que me conheço como gente. [...] O que que é isso tudo? É soja. Será que o ser humano come soja? Não, não come. Nós, Kaingang, nos alimentamos com plantas, dos nossos avós. (Entrevista com Iracema, Ẽmã Kandóia, junho de 2014).

E, com umas lágrimas caindo dos seus olhos, afirma: "Eu me lembro do meu irmão pela marca ${ }^{27}$ que morreu, eu estou fazendo o

\footnotetext{
27 Augusto Ópẽ da Silva, grande liderança kanhgág, protagonista nas retomadas de Terra em Iraí, que faleceu de câncer no dia 31 de maio de 2014.
} 
mesmo que ele, continuando a luta".

Ressalto aqui a importância das mulheres na luta pela terra. Não porque elas tenham um rol social específico em relação à luta, mas porque são protagonistas nas possibilidades de transformação do mundo. Iracema, como mediadora, permite a difusão de uma luta que já existe em Kandóia, mas que foi invisibilizada e silenciada. Tanto Malvina quanto Madalena, através das suas lembranças e de suas testemunhas, fazem viver seu território como Kaingang para além da sua comunidade. Aceitando a relação com Iracema, aceitando as substâncias na troca com Iracema, elas dão sentido ao trabalho xamânico de mediação que Iracema faz.

Nesse sentido, antes de tudo, o que coloca as mulheres ou os homens como protagonistas na luta pela terra não é uma divisão préestabelecida entre os domínios públicos e privados, mas sim uma questão de foco.

Chegando as três mulheres em Kandóia, Rita e eu fomos intensamente convidadas a entender as relações entre mulheres e, particularmente, entre jamrè como fundamental em momentos de tensão, como no caso do encarceramento das lideranças de Kandóia. O foco que em algum momento decidi colocar, foi em Iracema, procurando dar voz à luta pela terra a partir das próprias perspectivas de uma mulher kujà. Sua capacidade como xamã (seja como kujà, seja como mediadora entre as instituições governamentais e o mundo kaingang), à sua vez, ressaltou a importância da presença de outras mulheres para a continuidade da luta pela terra. Juntando saberes numa perspectiva relacional, Iracema se conectou com Malvina, Madalena, Cleci e Cleusa, saberes que dão, assim, continuidade à construção da cosmopolítica kaingang.

\section{Conclusão}

Além de ressaltar a importância das mulheres na constituição da cosmopolítica kaingang, os testemunhos aqui trazidos expressam o território kaingang como conectado tanto com tempos antigos expressado nas lembranças - quanto com seres do mato, destruídos 
pelos fóg. Os testemunhos das mulheres são um convite para pensar o mundo kaingang como intensamente relacional, e, assim, perceber as conexões existentes entre territorialidades diferenciadas e uma luta pela terra que se relaciona com a devastação dos seres que compõem essas territorialidades.

Os "trabalhos" de Iracema se vêm fazendo há anos, a partir de uma formação específica acompanhada por outras e outros kujà maiores. Esses demandam uma preparação e uma continuidade durante a vida toda. Esses saberes-fazeres cosmológicos são imprescindíveis em momentos de crises, como no caso do encarceramento das lideranças em Faxinalzinho. Além disso, esses momentos de crises estão sendo, nesse caso, conectados com outros momentos, passados, onde os trabalhos "xamânicos" foram também essenciais para a luta, e vitória do(s) povo(s) kaingang. Quando Iracema nos conta que seus trabalhos começaram aos seus nove anos de idade, no Paraná, foi também em um momento intenso de luta, pois seu pai, Penĩ, estava acompanhando a retomada da Terra Indígena de Mangueirinha, e conversou com ela, ao redor do fogo no chão, pediu para ela sonhar, para "ver" o que ia acontecer. Ela conta que no seu sonho, os Kaingang conseguiam retomar a terra, o que aconteceu logo depois. Na última viagem que a gente fez até Kandóia, Iracema pediu para parar na praça de Nonoai, descemos do carro e ela nos levou até o centro da praça, onde estava plantado um ipê muito alto. Iracema se aproximou da arvore e a abraçou por uns minutos. Logo me comentou que essa árvore era o lugar de conselho da sua comunidade em Nonoai, onde seu pai e outras lideranças se reuniam. Nesse sentido, o "xamanismo" conecta tempos diferentes ao redor de uma luta contínua pela terra. Os ensinamentos dos antepassados têm que ser valorizados e reatualizados no mundotempo atual, e essas reatualizações se fazem com um trabalho que, nesse caso, vai além de momentos específicos.

Como levar a sério o "xamanismo" kaingang quando se está devastando de maneira contínua os espaços que ele precisa para se desenvolver? Os discursos "ideológicos" dos políticos e órgãos estatais "indigenistas" sobre "o bem-viver" indígena acabam caindo numa contradição ontológica. Por um lado, valorizam-se, no discurso, os saberes e os ensinamentos "tradicionais" indígenas, e por outro, se está, 
com cada vez mais intensidade, destruindo os lugares onde estes ensinamentos estão levados na prática. Está claro, os conhecimentos dos kujà, kujà kajrẽn, não podem ser reduzidos ao "mato", nãn, nem muito menos a um "lugar". Trata-se, antes de tudo, de um saber-fazer relacional que, mesmo em contextos mais adversos, (talvez, sobretudo em contextos adversos), poderá se desenvolver.

Eu moro na cidade de Porto Alegre, no município ainda de Viamão, mas estou ainda na minha cultura, não esqueci o que meus avós me ensinaram, estou praticando com meus filhos, com meus netos e não é a cidade que vai fazer esquecer, e pretendo manter isso com meus netos, com a comunidade que convive comigo na periferia não só aqui, com Morro do Osso, com a Lomba do Pinheiro, e na São Leopoldo, cada semana estou indo lá, minha mãe mora lá, levando os remédios que ela pede pra mim, eu tenho que levar (Iracema, entrevista em 3 de outubro, na sua casa, bairro Jari, Viamão).

Esse saber-fazer relacional é uma clara forma de resistência e reafirmação de cosmologias dinâmicas que hoje, mais que nunca, precisam viver. Em outras palavras, trata-se de mecanismos de sobrevivência frente à ação colonialista do Estado brasileiro. Uma resistência que permite ainda aos povos kaingang uma margem de manobra e certa autonomia num contexto no qual se impõe constantemente sobre eles formas de pensar, viver e, sobretudo, se relacionar com a terra e seus seres, que se pretendem homogêneas e universais.

O "xamanismo" kaingang não está em "perigo de extinção"; porém, acho que não está demais ressaltar que a constante destruição dos "seres do mato" tem como efeito colateral a destruição de universos relacionais, fontes de aprendizagem e vida desses povos. Transformar o matão e as terras indígenas em cultivos de soja não fará com que os conhecimentos dos kujà kaingang desapareça, mas sim condenará esses povos, e todos nós, a sermos cada vez mais dependentes, à mercê de um sistema capitalista colonizador.

Como eu não estou na área demarcada, na reserva, pode ser uma reserva, pode ser uma área demarcada que o governo ainda não deu para nós, está difícil de 
colher meu remédio e para manter grandes trabalhos. Grandes trabalhos seria na minha área demarcada queimar as minhas ervas, atender minhas Kaingang grávidas e atender os guris que precisam dos meus banhos, mas aqui na periferia da cidade dificulta tudo. E meu desejo era isso, mas fazer o quê?, hoje nós é que precisamos, né? (Iracema, entrevista em 3 de outubro, na sua casa, bairro Jari, Viamão).

E por fim, nas palavras de Iracema, destinadas a todos os que se dispõem a ouvir, resumem muito bem a necessidade dos povos indígenas serem escutados sem ser considerados somente vítimas de processos coloniais e civilizadores. O "xamanismo", nesse caso, é um exemplo de protagonismo em seus próprios termos...

E os parentes que vão ver minha fala, espero que nós indígenas, o Kaingang no sul do Brasil é tão dificultoso pra nós ter o nosso trabalho, por falta dos governantes que não querem ceder a terra, mas a gente está levando e espero que vocês conheçam meus amigos e que vejam essa fala, que os parentes indígenas saibam, que eu, mesmo no meio da cidade, na periferia, eu não pretendo largar não, que isso é o meu trabalho, a minha cultura, que eu mantenho com orgulho e com amor (Iracema, entrevista em 3 de outubro, na sua casa, bairro Jari, Viamão).

\section{Referências bibliográficas}

ABU-LUGHOD, Lila. Writing against Culture. Santa Fe: School Of American Research, 1991.

ALBERT, Bruce. Territorialidad, etnopolítica y desarrollo: a propósito del movimiento indígena en la Amazonia brasileña. In: SURRALLES Alexandre; HIERRO Pedro García (Org.). Tierra Adentro: Territorio Indígena y percepción del entorno. Copenhague: IWGIA (International Work Group for Indigenous Affairs), 2004. p. 221258.

CARVALHO, Patrícia Rosa. "Para deixar crescer e existir": sobre a construção de corpos e pessoas Kaingang. 2011. 186 f. Dissertação (Mestrado em Antropologia Social) - PPGAS/UnB, Brasília, [2011].

CHAUMEIL, Jean-Pierre. Voir, savoir, pouvoir: le chamanisme chez les Yagua de l'Amazonie péruvienne. Genève: Georg Editeur, 2000. 
CREPEAU, Robert. Mito e Ritual entre os índios Kaingang do Brasil Meridonial. Horizontes Antropológicos, Porto Alegre, n. 6, p. 173-186, 1997.

ELTZ, Diego Duarte. Corporalidades Kanhgág: as relações de pessoas e corpo no tempo e espaço Kanhgág. 2011. 138 f. Dissertação (Mestrado em Antropologia Social) PPGAS/UFRGS, Porto Alegre, [2011].

FAVRET-SAADA, Jeanne. Les mots, la mort, les sorts. Paris: Gallimard, 1986.

INGOLD, Tim. Trazendo as coisas de volta à vida: emaranhados criativos num mundo de materiais. Horizontes Antropológicos, v. 18, n. 37, p. 25-44, 2012,

LANGDON, Esther Jean Matteson. Introdução: Xamanismo- Velhas e novas perspectivas. In: Xamanismo no Brasil: Novas perspectivas. Florianópolis: Editora da UFSC, 1996. p. 10-37.

LATOUR, Bruno. Por que a ecologia política não poderia conservar a natureza? In: Políticas da natureza: como fazer ciência na democracia. São Paulo: Bauru, 2004. p. 25-105.

NIMUENDAJU, Curt. Etnografia e Indigenismo: Sobre os Kaingang, os OfaiéXavante e os Índios do Pará. Campinas: Ed. Unicamp, 1993.

ROSA, Rogerio Reus Gonçalves da. Os kujá são diferentes: um estudo etnológico do complexo xamânico dos Kaingang da terra indígena Votouro. 2005. 416 f. Tese (Doutorado em Antropologia Social) - PPGAS/UFRGS, Porto Alegre, [2005].

SANTILLI, Paulo J. B. Usos da terra, fusos da lei: o caso Makuxi. In: NOVAES, Regina Reyes; LIMA, Roberto Kant de (Org.). Antropologia e Direitos Humanos: Prêmio ABA/FORD. Niterói: EdUFF, 2001. p. 81-136.

SILVA, Sergio Baptista da. Dualismo e cosmologia Kaingang: o xamã e o domínio da floresta. Horizontes Antropológicos, Porto Alegre, v. 8, n. 18, p. 188-209, 2002.

STENGERS, Isabelle. The cosmopolitical proposal. In: LATOUR Bruno; WEIBEL Peter (Org.). Making Things Public. Mit press, 2005. p. 994-1003.

VEIGA, Juracilda. Cosmologia e práticas rituais Kaingang. 2000. 304 f. Tese (Doutorado em Antropologia Social) - Curso de Antropologia Social, PPGAS/Universidade de Campinas, [2000].

WAGNER, Roy. A invenção da cultura. São Paulo: CosacNaify, 2010.

WIESEMANN, Úrsula. Kaingang-Português: Dicionário Bilíngue. Curitiba: Editora Esperança, 2002. 
CLEMENTINE MARECHAL - "OS PARENTES QUEREM A MINHA PRESENÇA"..

Recebido em: 26/01/2015 * Aprovado em: 05/06/2015 * Publicado em: 30/06/2015

Espaço Ameríndio, Porto Alegre, v. 9, n. 1, p. 151-181, jan./jun. 2015. 